\title{
POWERCELL SOLUTIONS FOR ENGINE FUEL CONSUMPTION REDUCTION
}

\author{
João Rafael Dezotti Neto, Everton Lopes da Silva, Eduardo Tomanik, \\ Eduardo Nocera \\ MAHLE Metal Leve S.A. \\ E-mails: joao.dezotti@br.mahle.com, everton.silva@br.mahle.com, \\ eduardo.tomanik@br.mahle.com, eduardo.nocera@br.mahle.com
}

\begin{abstract}
The Brazilian "Inovar-auto" tax program brings the need to improve engine fuel efficiency. In this paper, the impact on fuel savings by using low friction components was evaluated on representative Brazilian ethanol fueled engines. The vehicle certification cycles, and the typical urban drive, focus on low engine speed- loads where the mechanical losses are around $10 \%$ of the fuel energy. To define design changes on the engine components with more fuel saving potential, a proprietary simulation tool was used. After the selection of the design changes with greater potential, the engine was tested in a dedicated dynamometer cell with engine control, accuracy on fuel consumption measurement and fast acceleration transients needed to reproduce the fuel consumption cycles. The comparison between the baseline and the proposed lower friction components was done by 3 methods: a) motoring torque b) fuel consumption mapping, with average weights representative of the homologation cycles c) engine transient cycles, where the vehicle FTP75 and highway cycles were reproduced in the engine dynometer. The proposed lower friction components showed 2 to $6 \%$ fuel saving on the tested engines.
\end{abstract}

\section{INTRODUCTION}

The engine friction losses represent 1/3 of the passenger car fuel consumption, hence of the $\mathrm{CO} 2$ emissions [1, 2]. It is estimated that such losses can be reduced in $20 \%$ on the next 5 to 10 years and up to $60 \%$ on long term [2]. The friction losses are especially relevant in terms of fuel consumption at low speed/low loads typical of vehicle urban use and on the homologation cycles as the Brazilian "Inovar-Auto" and the FTP75 and NEDC emission cycles [3].

The piston rings and the piston represent around $50 \%$ of the engine friction losses [1] and for that reason, a lot of research and development work has been dedicated worldwide to reduce their friction losses. See figure 1 


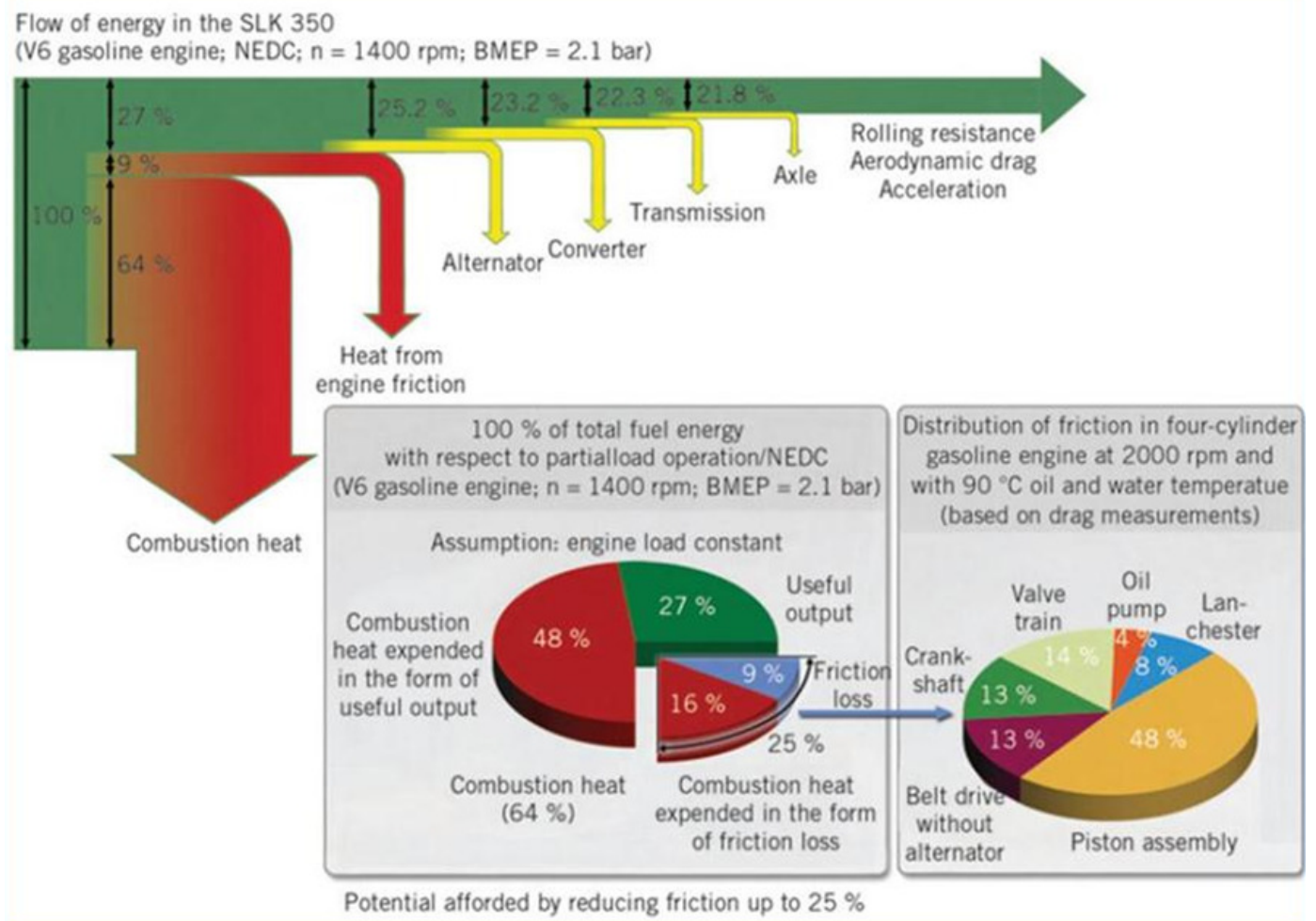

Figure 1- Engine energy flow in the NEDC cycle and the components friction share of internal friction. [1]

In Brazil, the use of flex-fuel engines allied with market cost sensitiveness, bring specific challenges on R\&D efforts to bring solutions to the market. As example, the higher tribological severity when using ethanol on the piston rings [4] brings some unique demands to flex-fuel engines. For the piston, the

different combustion pressure and thermal conditions, cause different thermal expansion and also need to be specifically studied before introducing a low friction solution in the market.

In this paper a method to quantify the friction losses impact in the fuel consumption and measuring the fuel savings under representative transient cycles is briefly covered.

\section{Estimation of fuel impact due to low friction components}

The share of friction losses depend of the engine and operation regime. The losses on typical flex-fuel engines [3] were mapped by MAHLE and a proprietary analytical tool to predict fuel savings with changes on component design and material/coatings was developed. With use of the prediction tool, the fuel impact on the emission homologation cycles can be estimated and a design change proposal can be done considering its benefits in fuel saving as eventual other impacts. See figures 2 and 3. Some of the concepts of the friction, fuel estimation tool are described in $[5,6]$. 


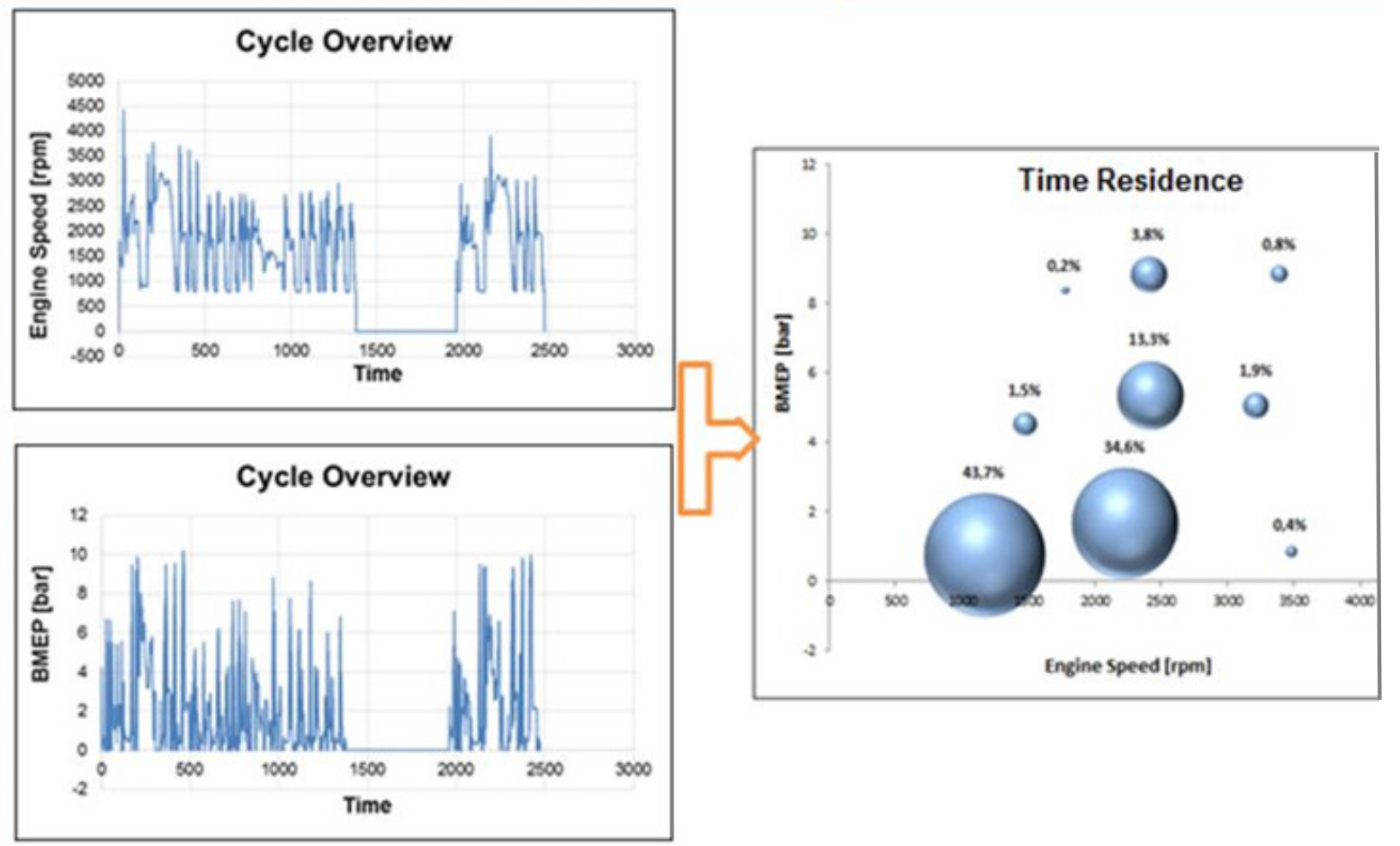

Figure 2 - Time residence of the Inovar-auto cycles for a given Flex-fuel vehicle.

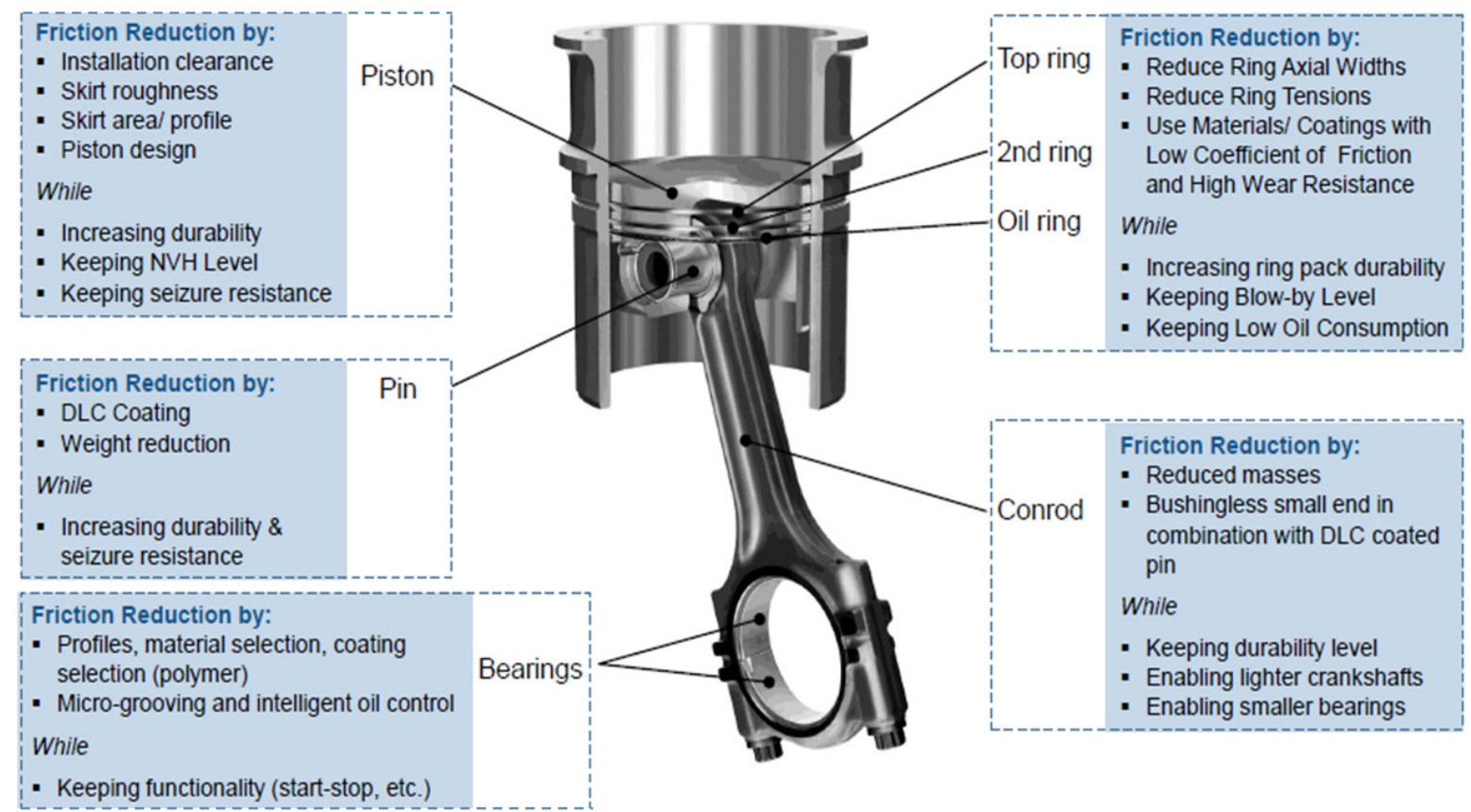

Figure 3 - Overview of friction reduction and operation requisites.

Figure 4 and 5 show, as example, one of design changes investigated in the Inovarauto demonstrators. The smaller piston skirt area reduces significantly the hydrodynamic friction losses and contributes for fuel savings. The design changes and friction reduction were first evaluated with use of dedicated tools as simulation of the mixed lubricant regime and mono-cylinder engines. The dedicated tools are able to predict or measure even very small changes, which would be impossible on a 
multi-cylinder engine. The fuel saving estimation tool integrates the individual contributions and predict the fuel saving of the complete PCU in engine operation conditions representative of the urban use and of the homologation cycles.

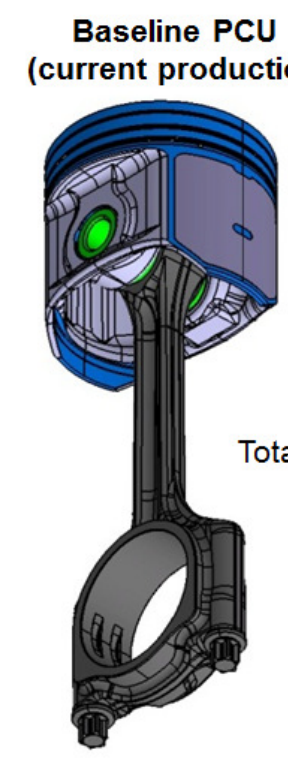

tion)

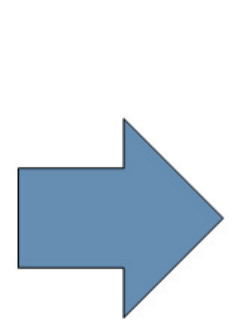

Increased Assembly Clearance

tal skirt area reduction: 4492,5 to $2402,8 \mathrm{~mm} 2(-46,5 \%)$

Reduced skirt roughness

Lower Ft Ring Pack: - 20\%

Total PCU weight reduction: 685 to $633 \mathrm{~g}(-7,5 \%)$

- Piston weight reduction: 257 to $203 \mathrm{~g}(-21 \%)$

- Pin weight reduction: 71 to $57 \mathrm{~g}(-17,7 \%)$
MAHLE Low Friction PCU (proposal)

Figure 4 - Production and the proposed low Friction PCU. [5]

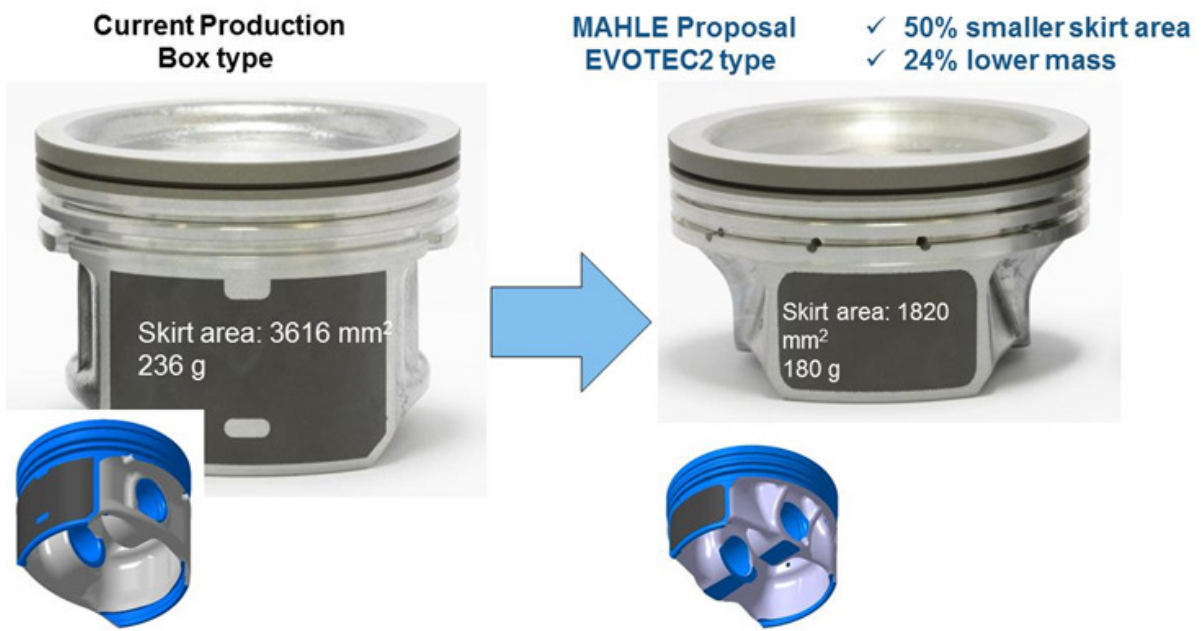

Figure 5 - Example of design changes of the Inovar-auto PCU demonstrators. [5]

The proposed EVOTEC2 ${ }^{\circledR}$ piston presents a stiffer structure that allows reduction of skirt area and profile optimization. Such features then allows increase of the assembly clearance without jeopardizing piston noise, scuffing and durability. Figure 6 shows the calculated asperity pressure of the production and the EVOTEC2 pistons. 

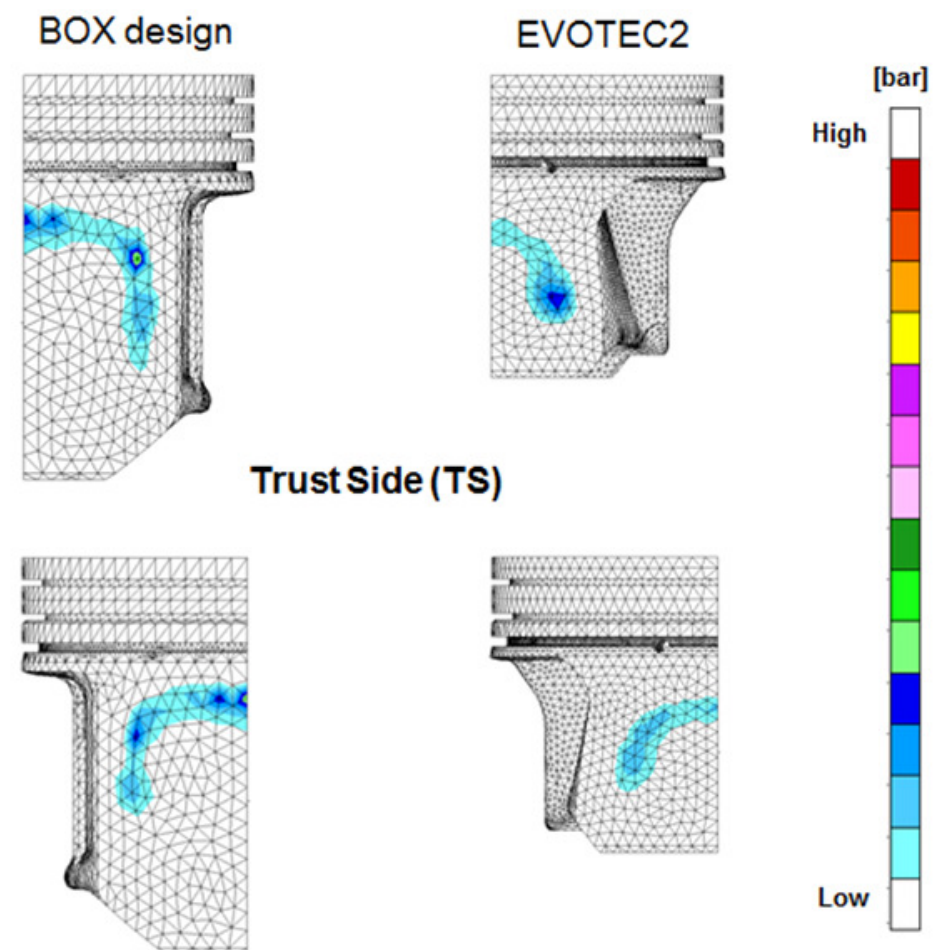

\section{Anti-trust Side (TS)}

Figure 6: Skirt total pressure distribution over $720^{\circ} \mathrm{CA}$ at Trust Side (TS) and antitrust side (ATS)

In terms of friction losses, figure 7 shows a numerical simulation was performed under rated power speed and load conditions, showing that the EVOTEC design reduces both the asperity and the hydrodynamic friction losses.

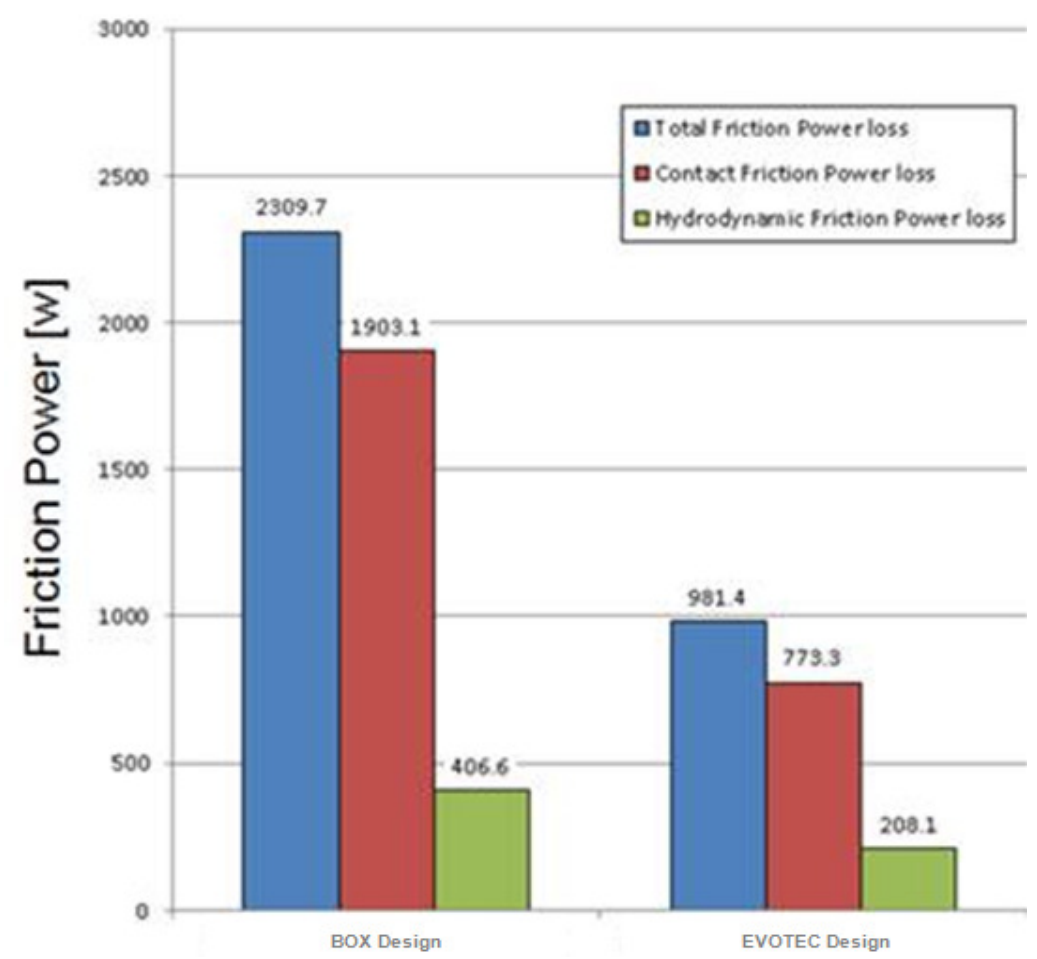

Figure 7 - Friction losses between current (left side) and proposal (right side). [5] 
The friction reduction features was confirmed on the floating liner test bench at speeds of 1,300 and 2,500 rpm. See Figure 8 . In the floating liner test bench, a cylinder liner is freely supported and can record frictional forces as a function of engine speed during fired operation.

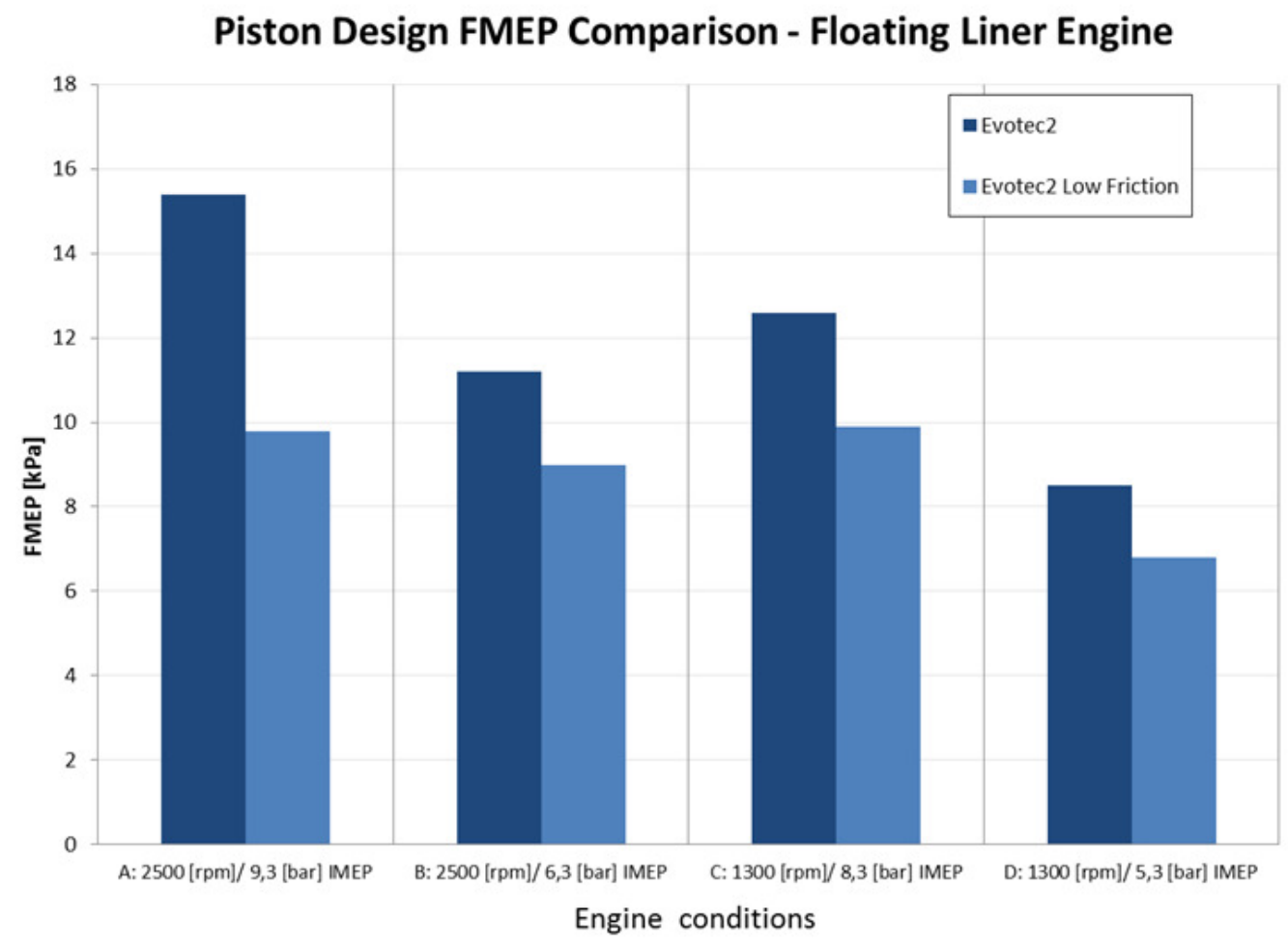

Figure 8: Friction mean effective pressure (FMEP) on the fired floating liner test.

\section{Engine tests}

After definition of the optimized PCU, the fuel savings are evaluated in the actual engine by comparing the proposal against the production version.

One of the comparisons is the measurement of the motored torque at 2000rpm with oil temperature in $90 \mathrm{C}$. The measured values are compared with an European published benchmarking [8] and helps to compare the different engines as well as the eventual potential for further friction reduction. Figure 9 shows 3 of the MAHLE low friction flex fuel demonstrators where 7 to $25 \%$ FMEP was observed.

More difficult is to measure accurately the fuel consumption changes, especially at low loads. A dedicated test protocol was developed by MAHLE Jundiaí Tech Center, called "MSC - MAHLE Simulation Cycle", this test protocol enable measure specific fuel consumption with high accuracy $( \pm 0.5 \%)$ on steady state conditions and dynamic cycles. In order to achieve this accuracy, a dedicated active dynamometer with state of art equipment (Coriolis fuel flow-meter, air, cooling water, lube, fuel temperature control and engine combustion control) was installed to support the PCU offers for the Inovar-auto program. 


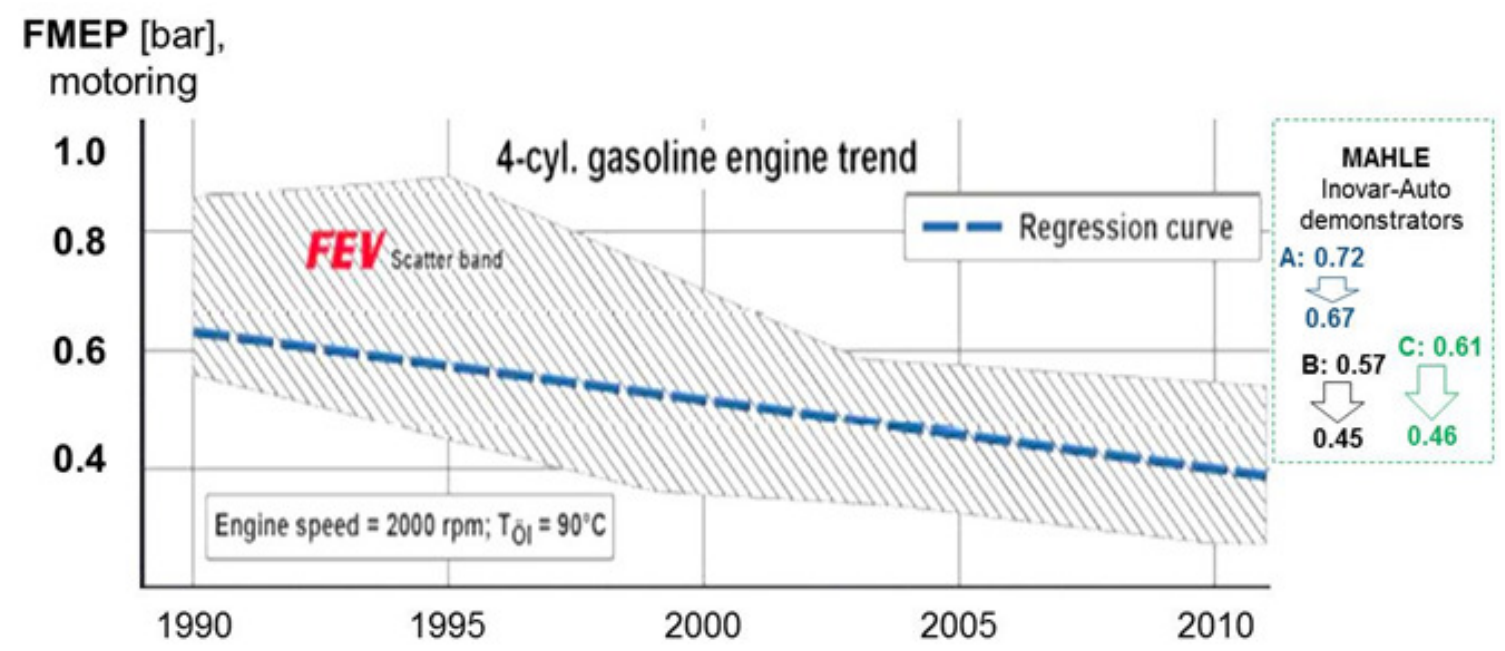

Figure 9- Measured FMEP of the production and the Inovar-auto demonstrators in comparison with European published data [8].

The engine with the production and proposed changes has the fuel consumption mapped on the complete speed, load envelope. The results are then condensed in the more relevant points as exemplified on figure 2 . The steady state mapping helps to identify the engine operation regimes were the friction losses and fuel consumption reduction were more significant and to check if the estimated savings were obtained. For that a weighting using time or fuel residences representatives of the cycle/vehicle are used. Figure 10 shows an estimation for the FTP75 urban cycle where the proposed PCU showed $2.7 \%$ fuel consumption reduction.

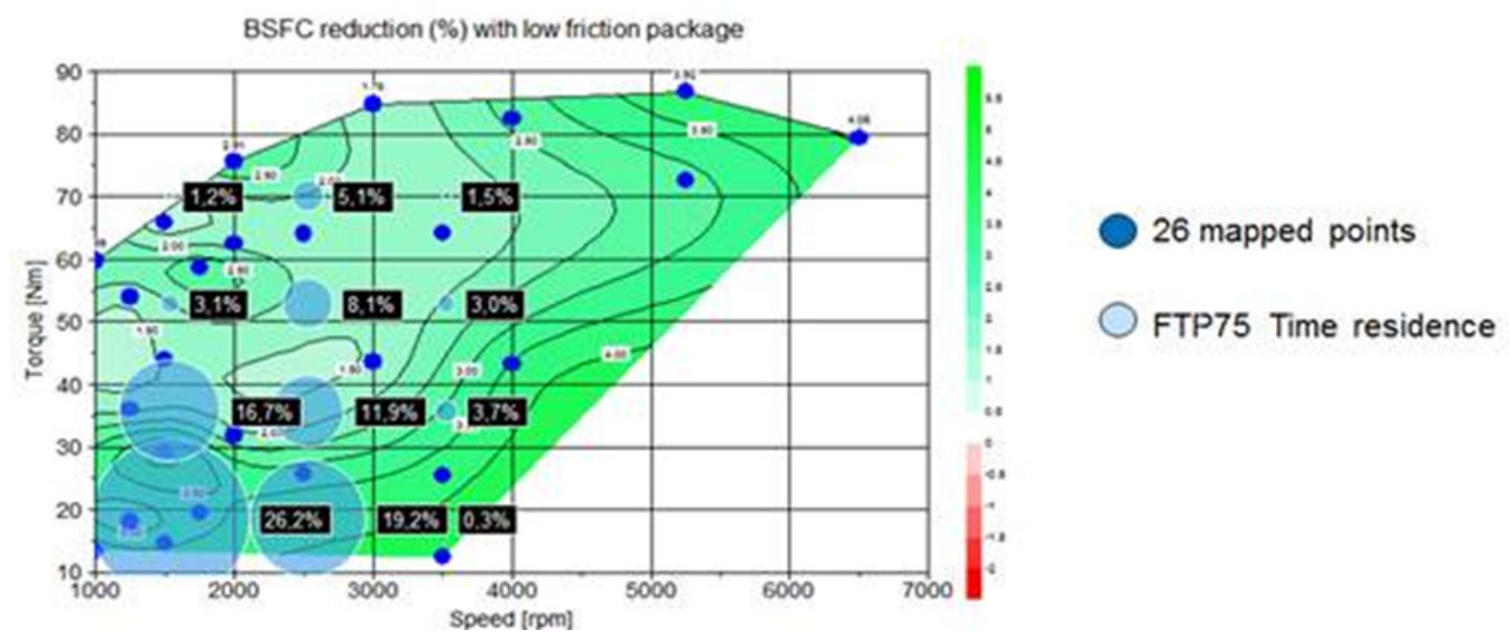

Figure 10- Measured torque along the FTP75 transient cycle.

For dynamic conditions, the official homologation cycles for INOVAR AUTO according NBR7024, FTP 75 and High Way, were reproduced on an engine dynometer following the procedure: 
- engine speed and throttle position were acquired along the vehicle transient cycles in chassis dynamometer and reproduced in the MAHLE engine dynamometer.

- the complete fuel consumption as well as the instantaneous engine speed, throttle and torque are acquired. Speed and throttle to assure that the transient cycle was accurately reproduced. The instantaneous engine power is calculated and later cycle integrated to evaluate the energy efficiency. With lower friction components the same throttle position leads to higher positive engine torque and lower drag torques. See example on figure 11.

- the integral of the positive and negative torques are separately numerically integrated along the transient cycle. The positive value is divided by the consumed fuel and serves as indicator of the energy efficiency. The negative value is compared with the motored torque under steady conditions.

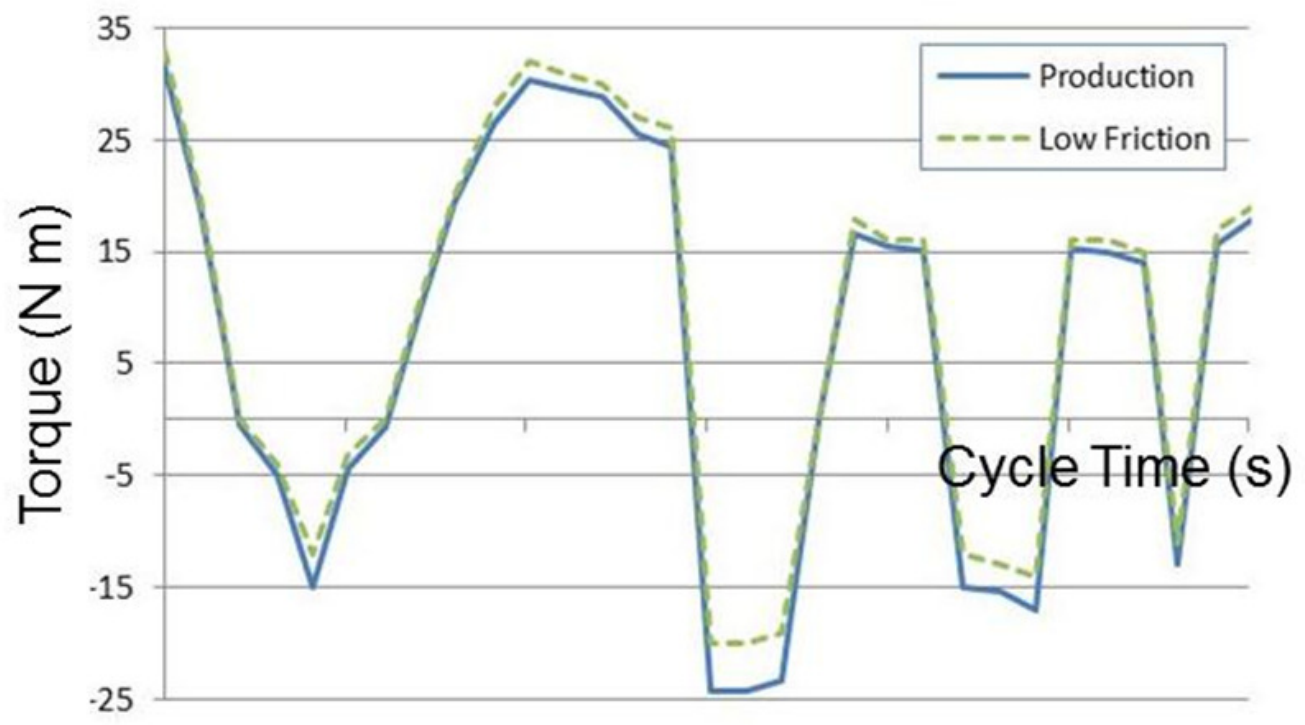

Figure 11 - Measured torque along the FTP75 transient cycle.

With the developed MSC engine test protocol the fuel consumption accuracy is better than chassis dynamometer measurements and the total time analysis can be reduced in $50 \%$ in comparison to chassis evaluation.

On the tested flex-fuel engines, the use of low friction components brought 2 to $3 \%$ higher energy efficiency on the Inovar-auto cycles.

\section{Conclusion}

With use of low friction engine components, currently available on the Brazilian market, fuel consumption and $\mathrm{CO} 2$ emissions can be reduced by 2 to $3 \%$. Such savings were demonstrated in a specifically developed methodology that reproduces the vehicle emission cycles in engine dynometer which allowed fuel consumption tests with higher accuracy and overall lower time for development that vehicle chassis tests. 


\section{References}

[1]- Schommers, J. et al. "Minimizing Friction in Combustion Engines" MTZ 0708/2013 vol. 74, 2013

[2]- Holmberg, K. Andesson, P., Erdemir, A. "Global Energy consumption due to friction in passenger cars" Tribology International 47, p.221-234, 2012

[3]- Fernandez, M., Tomanik, E., Carlini, R. "Comparison of the potential to reduce fuel consumption by engine energy losses mapping" SAE paper 2013-36-0221, 2013 [4]- Ferrarese, A. et al. "Piston Ring Tribological Challenges on the Next Generation of Flex-fuel Engines" - SAE International Journal of Engines 3 (2), 85, 2010.

[5]- Nocera, E. "Reducing Mechanical Losses for Fuel Targets on the Inovar-auto". $11^{\text {th }}$ symposium SAE of powertrain, Sorocaba, Brazil. Aug, 2013.

[6] Tomanik, E. et al. "Reduced friction power cell components" paper SAE 2000-01$3321,2000$.

[7] Tomanik, E., Ferrarese, A. "Low friction ring pack for gasoline engines" ASME paper ICEF 1566, 2006.

[8] Schommers, J. (Daimler) "Optimizing Friction: The Basis for Safeguarding the Future of Combustion Engines", Wien 2012 